\title{
Functions of Gichuka Discourse Markers in Gichuka Speech
}

\author{
Elsie Njeri Kirimo, Humphrey Kirimi Ireri \\ Chuka University, Chuka, Kenya \\ Email: elsiekirimi@gmail.com, irerih@yahoo.com
}

How to cite this paper: Kirimo, E.N. and Ireri, H.K. (2018) Functions of Gichuka Discourse Markers in Gichuka Speech. Open Access Library Journal, 5: e4931. https://doi.org/10.4236/oalib.1104931

Received: September 19, 2018

Accepted: October 26, 2018

Published: October 29, 2018

Copyright $\odot 2018$ by authors and Open Access Library Inc.

This work is licensed under the Creative Commons Attribution International License (CC BY 4.0).

http://creativecommons.org/licenses/by/4.0/

\section{(c) (i) Open Access}

\begin{abstract}
Discourse markers are linguistic items that are frequently used in the course of daily communication. These are not only connecting words that contribute to cohesion of discourse but are also crucial tools for achieving intended communicative purposes in the course of discourse. Studies have been carried out on discourse markers as used in other languages of the world but since every linguistic variety is unique and culture dependent, it is not obvious that these linguistic items are similar in all languages. This paper's goal is to discuss the functions of discourse markers Gichuka speeches. The study is guided by the Relevance Theory by Sperber and Wilson. It utilizes qualitative research technique and was carried out in Chuka, Meru South Sub County, Tharaka-Nithi County, Kenya. The population for this study includes all discourse markers captured in social events conducted in Gichuka. The researcher purposively sampled five real life events conducted in Gichuka. Data was collected using an observation schedule that was used to record the contextual information, and a guiding card was used to record the functions of discourse markers. The transcribed discourse markers are ninety-two. Guided by the principles of relevance the researcher identified and discussed the functions of all the discourse markers identified, taking into account the speakers meaning conveyed by the Gichuka discourse markers from various speech situations. The study established that most Gichuka discourse markers are used either to achieve conversational coherence in speech or to seek the attention of the audience. The study enhances the analysis of Gichuka discourse markers and adds to the existing knowledge on the analysis of discourse markers in various languages. It specifically enriches knowledge on the application of the tenets of the Relevance Theory. The study also contributes to scholarly literature in linguistics; especially in pragmatics.
\end{abstract}

\section{Subject Areas}

Linguistics 


\section{Keywords}

Functions, Gichuka, Discourse Markers, Speech

\section{Introduction}

A discourse marker (DM) is defined as an expression which signals the relationship of the basic message to the foregoing discourse. According to [1], discourse markers belong to a class of pragmatic markers incorporating elements which are outside the propositional content, implying that they are non truth conditional. They do not express a structural relationship between elements of discourse but they express relations between discourse elements which can be understood in terms of cognitive principles. DMs contribute to procedural meaning rather than conceptual meaning; they provide instructions to the addressee on how the utterance to which the discourse marker is attached is to be interpreted [2]. These are linguistically encoded clues that signal the speaker's potential in every communicative act.

According to [3] discourse markers have an important role in the interpretation of utterances and encode information about the inferential processes needed to interpret the relations between the utterances. Particularly, they have a significant role in spontaneous speech. When used appropriately, DMs act as a lubricant to refine the interaction between speakers though should not be associated with an undesirable or overused style of speaking. This is because absence of DMs renders the discourse neither ungrammatical nor unintelligible, but has great impact on communicative force and naturalness of its flow.

Interest in DMs has increased especially in regard to comprehension of extended discourse and, more generally, in pragmatic and contextual aspects of utterance interpretation. This increasing interest in the theoretical status of DMs has focused on what they are, what they mean, and what functions they have. This broadening interest brought about increased attention to those elements of linguistic structure that appear to be most directly involved in the relation of separate utterances. Within this perspective, these elements have required more attention, although they had previously been regarded as unworthy of close attention [4]. This study investigates Gichuka discourse markers.

A study by [5] examined the distribution and the use of discourse markers in the conversation of thirty Nigerian university graduates (NUGs) selected from three university towns namely; Ife, Kano and Nsukka. Evidence from a thirty hour recorded interview showed that discourse markers in the spontaneous speech of NUGs had different socio-pragmatic functions such as reparation, clarification and gap filling. It was noted that there was regional variation in the use of discourse markers depending on where they came from. This therefore, guided the researcher into treating Gichuka distinctively with unique linguistic features hence the study of Gichuka DMs. 
DMs occur more often in spoken than in written language. They are more likely to be used in situations where more than one speaker is involved. The occurrences of DMs are more than ten times as frequent in dialogues as in monologues. In conversations, lack of DMs makes a speech dull and in monologues, it makes it unappealing to listeners. Discourse markers, as a matter of fact, serve as more than attention catchers, and should not be taken as optional extras in speech. This means they function more than decorations in every interaction [6]. The interest of this study is spoken and not written discourse. The interest that prompted the scholars to carry out studies on DMs in different areas, similarly, prompted the current researcher to investigate whether DMs exist in Gichuka along with their functions in speech.

\section{Theoretical Framework}

This study was guided by [7] Relevance Theory. This is a theory in pragmatics which posits that most utterances are potentially ambiguous in more than one way. Thus, [7] states that an utterance makes manifest a variety of assumptions the hearer attends to as many of these seem as relevant to him. They further claim that the hearer mostly infers (deduces) the speakers meaning by considering what is and what isn't relevant to the current conversation.

It is further advanced by [7] that in an ongoing discourse, any new information that is added has contextual effect. They suggest that when the hearer perceives the contextual effect of new information in an utterance he or she will not only strive to interpret its "relevance" but also to find out in which way it can be used to clarify the speakers' meaning. During this communicative information exchange, any contribution by the speaker either "increases" or "weakens the strength of the hearers" assumption, deletes them altogether, or adds new beliefs. However, information that merely duplicates available information is perceived as being irrelevant to the already existing information. The most important type of cognitive effect achieved by processing an input in a context is a contextual implication, a conclusion deducible from the input and the context together, but from neither input nor context alone.

This study utilizes this theory to determine the Gichuka discourse markers that are used in Gichuka speech. This is by the expectation that speakers are able to use DMs in speech with the aim of guiding their targets towards the appropriate interpretation of their utterances. The speakers are able to do this because they expect the hearers to pick the most relevant meaning from their expressions informed by the input and the context of utterance. This study adopts communicative principle because it is concerned with utterances and their meanings in reference to DMs.

Guided by the principles of relevance, that a speaker may be able to produce a stimulus which is likely to attract the audience's attention, to prompt the retrieval of certain contextual assumptions and to point them towards an intended conclusion, and that the search for relevance is a basic feature of human cogni- 
tion which communicators may exploit, the researcher was able to categorize the linguistic items that Gichuka speakers use in speech as discourse markers under similar or different contexts for various functions. This is because a speaker is able to predict and manipulate their audience's mental states assured that the audience tends to pick out the most relevant stimuli in their environment and processes them to maximize their relevance with little effort. Here the speaker does not leave the listener with any other option other than what the speaker expects. In this study therefore, DMs are treated as stimuli that attract the hearers' attention hence guidance towards the speaker's intention. The theory enables the researcher to categorize DMs and to give their functions in Gichuka speech depending on context of use.

\section{Methodology}

This study utilizes qualitative research approach. The functions of Gichuka DMs are explained and the summary is presented in a table indicating the percentages for each function. The study was carried out in Chuka, Meru-South Sub-County, Tharaka Nithi County. The population for this study includes all Gichuka discourse markers in social events. The study adopted the purposive sampling technique to arrive at real social events conducted in Gichuka that are used in this analysis.

The researcher limited the study to five real life social events and recorded the entire speeches. These included family meetings, chief's barazas, church meetings, wedding functions and burial meetings. The events generated enough data for the study. Though the researcher had collected data from more social events, analysis beyond this would have been repetitive. Data was collected using a guiding card and an observation schedule. The guiding card captured the Gichuka DMs with their functions in the selected social events. The observation schedule was used to record the contextual information which was used to determine the types of DMs and the functions they served in various or similar context.

A research permit was sought from the National Commission for Science Technology and Innovation. The researcher also wrote a letter of introduction to aid in data collection. Permission was sought from conveners of the social events and permission to record and participate in the events was granted. Research ethical considerations were followed and the researcher promised confidentiality in dealing with the data collected. The real names of the speakers were not used in the study except the titles of some who are public leaders and the social events in which they participated willingly and publicly.

\section{Functions of Gichuka Discourse Markers in Speech}

The functions of Gichuka discourse markers are discussed as they feature in various social events following the formulated guiding card. Context of utterance is considered a key factor in the discussion of the functions of these DMs. The 
functions of Gichuka DMs are discussed in the following topics: Conversational coherence, filler words, attention seeking DMs, request for agreement or confirmation DMs, and demarcation DMs.

\subsection{Conversational Coherence}

Discourse markers serve various functions in Gichuka speech. Various DMs served this function in social events addressed in Gichuka.

Social event one (SE.1) is an occasion where members of a given family from Chuka whose daughter had returned home unhurt from Garissa terror attack and so they had invited members of the community and also the clergy for a thanksgiving ceremony. The speaker was a retired chief. The examples of the markers that served the function of conversational coherence were discussed as follows, SE 1:2 and SE.1:4.

SE 1:2 achieves conversational coherence because the speaker is able to link up what he has introduced with the context; that is, whatever had brought these people together. An indication that "Niuntu" is used here to bring about linkage with the proposition that the speaker uses to capture the attention of the audience at this point. According to [8], additional consideration to the special interactional function of discourse markers when used in conversation should therefore not be ignored since it describes how participants in a conversation mutually work at establishing an understanding during discourse production thereby emphasizing on the same. The speaker here, alludes to reference to God in order to sound convincing to his audience. SE.1:4 achieves conversational coherence that shows the relevance of God to peoples' lives in all situations because it was by the grace of God one of them was able to get out a very bad situation safely. Consider SE.1:6 and SE.1:7.

Discourse markers belong to a class of pragmatic markers incorporating elements that are outside the propositional content. This is because DMs have an important role in the interpretation of utterances for they encode information about the inferential processes needed to interpret the relations between the utterances. If used appropriately, DMs act as a lubricant to refine the interaction between speakers. Fraser also argues that these important words should not be associated with an undesirable or overused style of speaking [1]. Looking at what Fraser says about DMs, this clearly indicates that DMs are very important in Gichuka speech. The speaker used SE.1:6 "nikenda" while surveying the context, the parents of this student did not want her to go to Garissa University but to another university nearer home owing to insecurity reasons and so the DM functions to achieve conversational coherence at this point. Still looking at what Fraser says about these linguistic features, SE.1:7 makes the argument by the speaker relevant in this context for it convinces the audience that the concerned parties had tried their part but it had not been possible for their student to be admitted in any other university. Let us look at SE.1:8, SE.1:10, SE.1:11, SE.1:12 and SE.1:14. 
Borrowing from the Relevance Theory, the researcher was convinced that the speaker had the power to manipulate the listeners' mind towards the conclusions he would wish them to draw. Therefore, the DM "kwogu" in SE.1:8 establishes relevant relations between these discourse units through binding the propositions within the same context, hence the required cognitive effects. This is because the speaker struggles to convince the audience that these people really had tried other avenues but failed to get any assistance. SE.1:10 brings out conversational coherence highlighting that the university was like any other in our country. SE.1:11 "Eee na kwogu" helps to bring about conversational coherence because the utterance emphasizes on the power of God that the speaker had mentioned earlier, because as noted, their daughter had gone through real torture but there was clear evidence that God had protected her. This is further enhanced in SE.1:12 because, the speaker uses it to appreciate the fact that members of that family had noted the need to appreciate the deeds of God since it was the main purpose of that function. SE.1:14 brings about conversational coherence since it exhorts selflessness amongst the audience who the speaker persuades to remember in prayer, other families that were affected by the same.

Social event two (SE.2) is a Chief's Baraza. The speaker is the chief who tries to persuade members from his area to attend a meeting that was important for vital decisions would be made. The following are the DMs that were realized from the speech. Let us now focus on SE.2:2, SE.2:5, SE.2:6, SE.2:10 and SE.2:11.

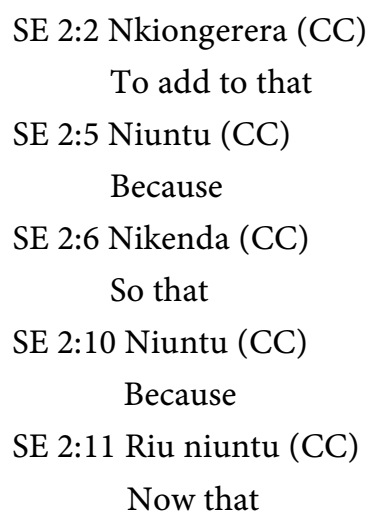

SE 2:2 functions as a contextual link between the segments yet it does not affect the propositional content in the segments. SE.2:5 shows doubt that from previous experience according to the chief, people from this locality do not attend meetings and so the speaker struggles to remain relevant by noting that if they don't get represented, others from other areas will get the advantage. The speaker uses this marker to stress the need to attend the said meeting.

According to [7] any new information that is added in an ongoing discourse has contextual effect. This is because when the hearer perceives the contextual effect of new information in an utterance, he or she will not only strive to interpret its relevance but also, to find out in which way it can be used to clarify the speakers meaning. The most important type of cognitive effect achieved by processing an input in a context is the conclusion deducible from the input and 
the context together, but from neither input nor context alone. Borrowing from the relevance Theory therefore, what the speaker says in SE.2:5 "niuntu" then, strengthens the hearers assumption as expected by the speaker in this context. This helps to lead the hearer towards the right interpretation of what the speaker says at a particular point, hence linkage. SE.2:6 emphasizes that the process will go on even if any group fails to attend. This marker strengthens conversational coherence in this context, hence relevance. SE.2:10 still puts emphasis on the topic and helps to achieve conversational coherence too.

SE.2:11 could be used to achieve a number things here but the most relevant function the marker does, is that it works to capture the attention of the audience by showing the contradiction and so furthers conversational coherence. This leads to the right interpretation within the available context because, it encodes the inferential information required to direct the hearer towards the right interpretation of this utterance. SE.2:12 is a DM that puts emphasis on the same topic that the hearer should attend the said meeting because it is important. Therefore, it serves the function of conversational coherence, because it supports what had already been earlier alluded to.

Social event three (SE 3) is a church meeting where the first speaker was a Sunday school teacher. Here the speaker persuades the congregants to support Sunday school. The second speaker was the preacher who presented the sermon on selflessness. That day participants were church members, who included the clergy and the speakers. Let us now focus the DMs that were used to achieve conversational coherence in SE.3.

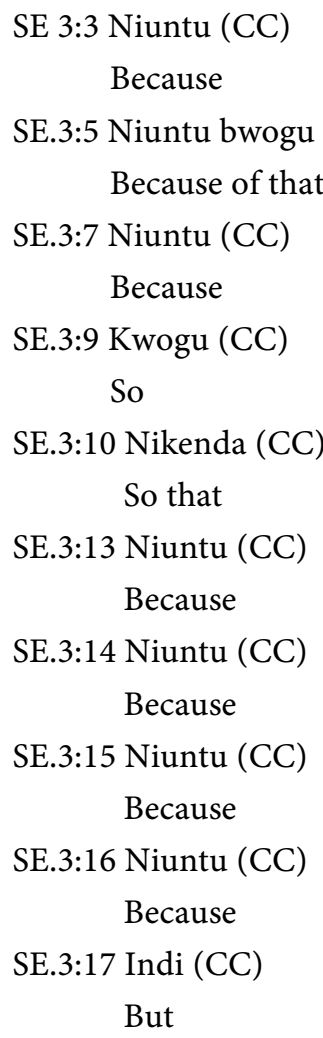

Conversational coherence, enhanced in SE.3:3, contextually links this utter- 
ance to SE.3:4 which is a DM that is emphatic on the topic and therefore persuade the hearer to listen to the speaker, as it continues to link what the speaker says within the context. This allows this utterance to be relevant within this conversation. SE.3:5 is used to expound on the initial topic thereby, taking care of conversational coherence within the same context. SE.3:7 was relevantly used to help achieve conversational coherence within this segment and the previous segments because it shows connectedness within the same context. That is, the Sunday schoolteachers had the welfare of the children at heart because they had a major role to play in nurturing these children into responsible members of the society. Contextually the speaker used this DM in a way to convince the congregants into accepting the decision the teachers had made. According to [9] posited that when speakers talk, they do so with the expectation that speakers are able to use DMs in speech with the aim of guiding their targets towards the appropriate interpretation of their utterances but still constraining the utterance inferentially. This is because the speakers expect the hearers to pick the most relevant meaning from expressions informed by the input and the context of utterance. In this case, the speaker uses this choice of a DM to guide his targets towards the right interpretation.

Looking at SE.3:9, it is evident that this is a DM that the speaker used to requests the parents to always prepare their children in good time hence brings correlation in the conversation and coherence is achieved within the context. Also, SE.3:10 brings about persuasion showing that the parents should take the situation as important as the teachers had done to be able to mold the children into responsible members of the society in this context. "Nikenda" in SE.3:10 is a DM that persuades the hearer to agree with the decision by the Sunday school teachers. Here the second speaker has just taken over from the first speaker (Sunday schoolteacher). SE.3:13, SE.3:14, SE.3:15 are used to achieve conversational coherence within the topic and context.

SE.3:16 is a DM that the speaker uses to maintain the context and to emphasize that selfishness was a vice that should be discouraged. This enhances conversational coherence. SE.3:17 also serves to remind the audience about the same vice thereby holding the conversation within the context.

Looking at social even (SE:4), is a burial function with two speakers A and B who are senior political leaders addressing and condoling with the bereaved family. The political leaders noted that the members of the community had died of terminal ailments like cancer because the county had not invested enough in medical care. The political leaders emphasized on working towards improving the medical facilities in the general hospital in the county. The DMs that were used in this context to achieve conversational coherence were summarized as follows: "Niuntu" (because) appears in; SE 4:2, SE 4:11, SE 4:15, SE 4:17, SE 4:19, SE 4:22, SE 4:25, SE 4:26, SE 4:32, and "Nikenda" (So that) as in; SE 4:5, SE 4:13, SE 4:28, SE 4:31, SE 4:34. Others realized from the same context are as follows.

SE 4:6 Indi nikumenya tiri (CC) 
But I know that

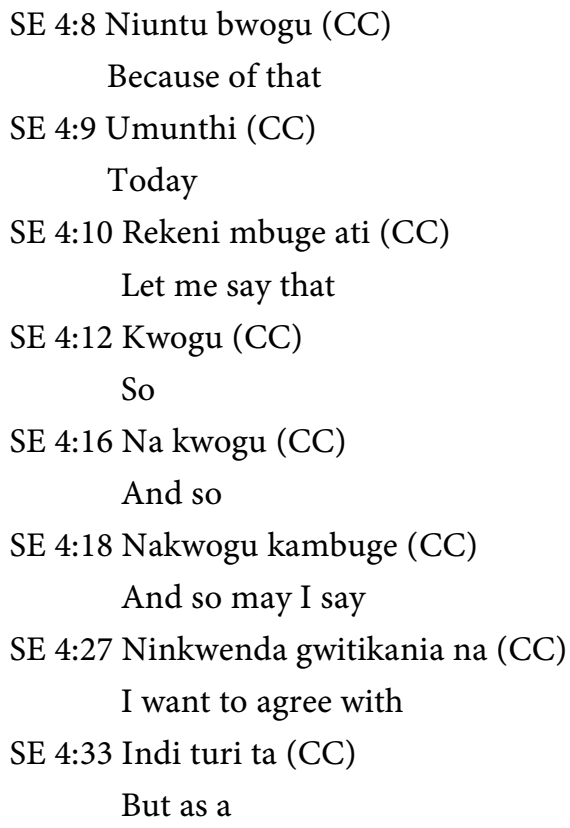

SE 4:2 "niuntu" (because) is a marker that is relevant depending on the context (burial) that still holds the unity of the conversation because the speaker has just introduced his talk. SE 4:3 contextually justifies every reason of support accorded to the family of the deceased because friends had given a lot of assistance in terms of medical care of the deceased, which was good for it encouraged social unity.

Speaker A uses the DM in SE.4:5 to change the listeners' attitude towards the county government by alluding to the fact that the county government had not done enough as far as the health of the people is concerned. This is relevant on the part of the audience that hails from his county understands this speaker's political interest in 2017 when he intends to capture the gubernatorial position. This DM helps to achieve conversational coherence at this point. SE.4:6 also puts emphasis on the above hence strengthening conversational coherence. Here the speaker helps the hearer by reducing the cognitive effort required through the use of the linguistic forms in his utterance to guide the interpretation process as expected by the hearer. This is because, according to [7], any information that requires excessive cognitive energy for interpretation is not worth processing. Going by this therefore, this DM helps in lessening the energy required for the correct interpretation.

SE.4:9 and SE.4:10 are DMs that achieve the unity of this conversation within this context because they have been used by the speaker to relevantly bring in a different point about the medical scheme that the public had been complaining about because it was too expensive for the people. The speaker agrees to step in to ensure the medical scheme is affordable. According to information carried in the proposition introduced by these DMs, Borrowing from relevance theory by [7] that claim that the hearer mostly infers (deduces) the speakers meaning by 
considering what is and what isn't relevant to the current conversation. The above DMs therefore are considered to have added to the relevance of the proposition, which leads to appropriate interpretation. Considering SE.4:11 "niuntu" (because) "the speaker has to first agree with his people, so that he does not seem to be blocking whatever decision that is likely to help his people in any way", although, he indeed argued that the right procedure was not considered.

The marker in SE.4:12, maintains the coherence of conversation in the utterance. SE 4:15 "niuntu" (because) and SE.4:16 are used to achieve conversational coherence because speaker B struggles to still remain within the context for he considered it a great favor to have been allowed a chance to speak to the mourners because that was not obvious. In SE.4:18 and 19), "niuntu" (because) speaker $\mathrm{B}$ also agreed that his county had lost several people because of diseases that could have been managed if the county had been able to invest more in the health sector. This is further justified through SE.4:22 "niuntu" (because) and SE.4:23, which helped to achieve inferential relations within the conversation and context, hence maintained the attention of the audience.

Speaker B employs the DMs in SE.4:25 and 26 "niuntu" (because) to achieve conversational coherence. These DMs still support the previous segment within the same context when he goes further to give the reason behind not speaking about political matters since his major intention was to condole with the bereaved family in this context. SE.4:28 is a marker that relevantly supports better medical care, which is the choice of the people. This further enhances conversational coherence. SE.4:31 and SE.4:32 "niuntu" (because) are markers that give the reason behind revising the scheme taking into account all classes of people in the society. This helps to achieve conversational coherence in this context. SE.4:33 has pragmatically been used to arrest the attention of the audience because it alludes to the topic about the hospital and supports what speaker A had said about the same. SE 4:34 also enhances conversational coherence in the same context.

Looking into social context five, (SE 5) is a family meeting, where the speaker here was the master of ceremonies (MC). Let us focus on SE.5:3, SE.5:7, as brought out in this context.

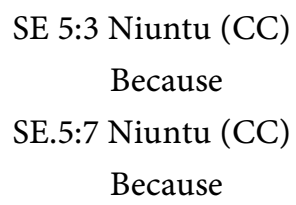

The master of ceremonies used the DM in SE.5:3 to achieve conversational coherence by explaining why the occasion was joyous. SE 5:7 helps to achieve conversational coherence since the speaker was stressing the same idea-importance of friendship.

\subsection{Turn-Taking}

The following are the example of turn taking DMs that were realized from the 
five social events.

In social event one, SE.1:3 "Kiambiriria" is a turn taking DM the speaker uses indicate that he had begun to speak and this helps to persuade the listeners into listening to what the speaker was saying at that particular time.

SE 1:3 Kiambiriria (TT)

\section{First}

The DM in SE.2:1 "Nkiambiriria" in social event two is another example of a turn taking marker. This is because this DM serves as a signal to turn taking with an indication that the turn belongs to the speaker.

SE 2:1 Nkiambiriria (TT)

\section{As I start}

SE.3:1 "Niwega" in social event 3 was also treated as a turn taking marker in this context since we had two speakers in this event. The Sunday schoolteacher used the DM to establish her turn.

SE.3:1 Niwega (TT)

$$
\text { It is well }
$$

The DM in SE 4:1 "Nkiambiriria kambuge" is a marker that the speaker uses to open up his speech and to call for the attention of the mourners within this context. It is therefore treated as turn taking DM.

SE 4:1 Nkiambiriria kambuge (TT)

$$
\text { As I begin may I say }
$$

SE.5:1 used in social event 5 is a turn taking DM because the master of ceremonies used it to open his speech in the context where he appreciated the fact that members of their extended family had attended the function. This was relevant because this was a family function.

SE 5:1 Niwega, niuntu (TT)

It is well because

\subsection{Filler Words}

Discourse markers are used as filler words when the speaker, in the course of speaking, realizes through feedback that his speech is not acceptable for some reason. Since the speaker has to struggle to remain relevant in the conversation, he or she employs a filler word as he or she finds the appropriate word to use within the context. The following are examples of filler word that was realized in SE.1 which was a thanksgiving ceremony.

SE 1:5 Mmm... (FW)

SE 1:5 above is a filler word that allows the speaker to reorganize his speech. This was important here because the issue that he was addressing was very sensitive that required proper choice of words. According to [10], filler words are used to indicate that the speaker has difficulty formulating what he is saying, while speaking cannot find the contextually correct word. Borrowing from [10] the above speaker identifies with the context and he uses the filler word mmm... to be able to get the right word that would fit in the context without hurting the 
feelings of his audience.

Further, the second social event (SE.2) is a Chief's Baraza, where the following DM was realized from the speech.

$$
\text { SE 2:8 Naa... (FW) }
$$

And...

The speaker uses the DM in SE.2:8 as a filler word that gives the speaker time to think up the right word so that he can give reliable information considering his position. This agrees with [10]'s, and [4]'s stand on filler words, that they help the speaker to think of the most appropriate word during a speech. Borrowing from Rowling and Andersen, therefore, this DM allows the speaker to quickly get the most appropriate word that serves the required purpose within the context. Examining social event three (SE 3), it is a church meeting where the speakers are a Sunday school teacher and a preacher who presented a sermon on selflessness. The participants were church members. Consider SE.3:6.

SE.3:6 Eee... (FW)

The filler word in SE.3:6 is emphatically used in support of the previous segment and it also allows room for conversational coherence, though the most important function here is to enable the speaker to think up the exact word that suits the context.

\subsection{Attention Seeking DMs}

Several DMs were found to serve this function in Gichuka speech. Social event one (SE.1) is a family thanks giving ceremony. The speaker was a retired chief. The following are examples of the markers that served the function of seeking for attention from the audience within this context.

SE 1:1 Ninkwenda kumukethia mwinthe (AS)

I want to greet you all

SE 1:9 Indi (AS)

But

SE 1:13 Kana tibu? (AS)

Isn't it so?

SE 1:16 Niuntu (AS)

Because

Borrowing from [11], SE.1:1 is a marker that the speaker uses to call for the attention of the audience to the context, as the speaker establishes that it is his turn to address the gathering. The DM in SE.1:1 helps him to win the attention of the audience to what he was saying at that particular time.

Speakers use discourse markers to request attention from the audience. In the above context the DM ninkwenda kumukethia mwinthe (SE.1:1) appears at the beginning of the speech as a form of greeting, but the main purpose pragmatically, is to call for the attention of the audience. SE 1:9 is an attention seeking DM that clearly showed that the concerned were not comfortable taking their daughter to Garissa. This DM is pragmatically used at this point as an attention 
seeking DM and not as a contrastive marker, if semantically considered. It is meant to make the point clear to the audience that, the circumstances under which they took their daughter to the mentioned university were beyond their control. Within the same context, the speaker still claims the attention of the student as he reminds her in SE.1:16 that she was a sure witness of the deeds of God and so should live by his will so that when she joins another university she must not forget the far God had taken her.

The second social event (SE.2) is a Chiefs' Baraza and the speaker is the chief. The following are the DMs that were realized from social event two.

SE 2:3 Ngiciokereria (AS).

To repeat

SE 2:4 Riu (AS)

Now

SE 2:9 Tathikiririani baba wega (AS)

Just listen carefully to this

SE 2:12 Ngiciokereria tathikiririani (AS)

As I repeat, listen

SE 2:3 in its context works as an attention seeking DM. This DM is geared towards making emphasis on what is being said thereby, binding the audience within the same context. SE 2:4 works in a manner to alert the listeners that the speaker was saying something and so the hearer should listen because from earlier experience these people do not pay attention to information. The DM "riu" shows doubt as the speaker emphasized the fact that attendance was important for proper representation. The speaker uses this marker to capture the attention of the audience within this context. SE.2:9 is a DM that is emphatic and as result, strikes the attention of the listener and this helps in constraining the interpretation of the utterance by the hearer about the importance of taking the matter seriously. According to [7], the expectations of relevance raised by an utterance should be precise enough, and predictable enough, to guide the hearer towards the speaker's meaning. Alluding to this then, this DM guides the hearer towards the speaker's expectations for it serves the function of seeking for attention from the hearer. SE 2:12 continues to persuade the listener to pay attention which the speaker is quite emphatic about.

There are two speakers in social event three (SE 3). The first speaker is the Sunday school teacher and the second is the preacher. A number of DMs were used by the speakers to seek for attention from the audience in this social event. Let us consider SE.3:1, SE.3:2, SE.3:18, SE.3.19 and SE.3:20.

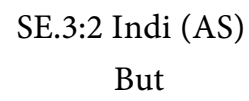

SE.3:18 Oooo... (AS)

SE.3:19 Atumia Oyi... (AS)

SE.3:20 Athuri Oyi... (AS)

As realized in SE.3:2 the DM "Indî" seeks for attention of the audience and 
that also justifies the option that the church school teachers had taken. The three DMs in SE.3:18, SE.3:19, SE.3:20 all serve the function of seeking for attention from the audience. The speaker used the DMs in SE.3:19, SE.3:20 within this context to be confident that she had both factions of the congregation on board.

Social event four (SE.4) is a burial function. The speakers were Political leaders addressing mourners during a burial ceremony. Both speakers had attended to condole with the bereaved family and at same time get the opportunity to address the people from the county. Let us consider the following DMs.

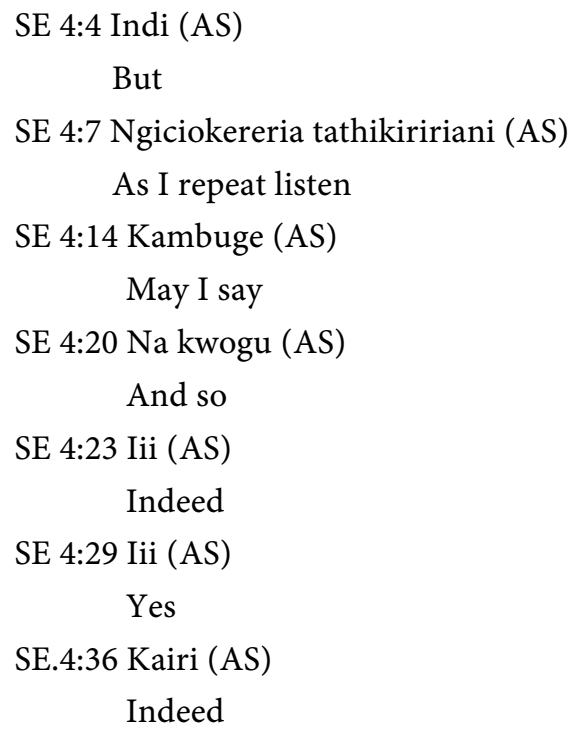

Looking at SE.4:4 contextually, it is clear that it holds the conversation because it talks about the same topic, a relatedness that makes the utterance relevant in this context. The speaker at this point manages to retain the attention of the audience when he talks about the much that needed to be done to safeguard peoples' health. Speaker B also attends the burial and after giving his apology, he goes ahead to thank the Reverend for giving him a chance. The Utterance in DM SE.4:14 fits in well in this context as it attracts the attention of the audience towards what the speaker was saying; that he fully understood the procedures of that church and so was grateful for the chance that he considered special, an indication that it was a favor.

The DM in SE.4:20 achieves a lot in this context for it allows the audience to understand that the county had indeed lost one of their own, who could not have died if at all proper measures had been put in place and in good time. This captures the attention of the audience. SE.4:23 also helps to achieve coordination within the conversation and context by capturing the attention of the audience because of the weight it carries in its emphatic nature. SE.4:29 is a marker that emphasizes the seriousness of what the speaker has already said therefore strengthening the attention of the hearer. The speaker uses the DM in SE.4:36 to persuade the audience to believe in the existence of God.

Social event five (SE 5) is a family meeting where one member of the family is seen to have brought his fiancee home. The speaker here was the master of ce- 
remonies (the MC). Let us now focus on SE.5:2, SE 5:5.

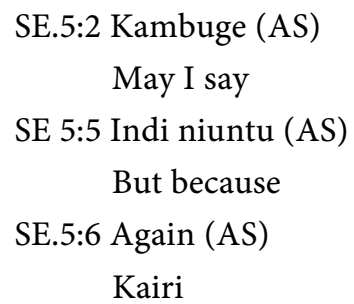

SE.5:2 is a DM that the speaker used to remind the hearer about the actual function hence capturing the attention of the audience within this context of a family meeting. The same hope of a lasting friendship extended in SE.5:5 by the DM with the expectations that the guest would have time to also meet others who were absent at that time. This still enhanced the attention of the audience. The DM in SE.5:6 is used to emphasize that indeed these people were really excited about the visit of their friend. The speaker used this DM at this point to bring to the attention of the audience that the friendship should not be taken for granted.

\subsection{Request for Agreement or Confirmation DMs}

In conversations, we sometimes ask a question, not because we need information but to confirm what we already know. We want the person addressed to agree with us. This is done in the form of a question and in this research, such questions are treated as DMs. Let us consider this in the following social events.

Social event three (SE 3) is a church meeting where the speakers were the Sunday school teacher and the preacher. Consider SE.3:4 and SE.3:11.

SE.3:4 Turibamwe kanitha (RAC)

Are we together church?

SE.3:11 Kana tibu kanisa? (RAC) Isn't it so church?

SE.3:4 is DM that is emphatic on the topic and therefore persuade the hearer to listen to the speaker, then; it continues to link what the speaker says with the context which surrounds this utterance. This allows this utterance to be relevant within this conversation and also to connect with the context. The DM in SE.3:11 is used by the speaker to persuade the congregation to agree to what was being said at that time because it would benefit the children.

Social event four (SE.4) is a burial function. At this point speaker B is a Political leader who addresses mourners during a burial ceremony. The leader was quick to agree that members of the society had died of terminal ailments that could have been managed if the county had proper investment in medical care. The speaker emphasized on the urgent need to make the general hospital a model medical facility. Let us consider SE 4:24.

SE 4:24 Kana tibu (RAC)

Isn't it so

SE.4:24 is contextually used by the speaker to request for agreement from the 
audience now that he was already addressing something sensitive.

\subsection{Demarcation Markers}

Demarcation markers are used when one wishes to clarify something or as conversational openers. The following are examples of markers for demarcation that were found in Gichuka speeches, in various social events.

Social event (SE1) was a thanksgiving ceremony. A given family celebrates because of the safe return of their daughter from Garissa terror attack. The speaker was a retired chief. Let us look at SE 1:3 and SE 1:15.

SE 1:15 Nkirikiriria (MD)

As I finish

Considering the context, the DM in SE.1:15 "Nkirikiriria ri" is purposeful as a marker of demarcation that the speaker uses to alert the audience that he was approaching the end of his session but still holding it within context. Then, the speaker notes that their student would be joining another university, and wishes her well.

Social event two (SE.2) is a Chief's Baraza. Let us look at the DMs that were realized from the social event. Consider SE 2:1, SE 2:7 and SE 2:13.

SE 2:7 Bwakairi (MD)

Secondly

SE 2:13 Nkirikiriria ri (MD)

As I finish

SE.2:7 serves as a marker for demarcation because it shows that the speaker is making some transition from what he had been saying as well as linking the context with the previous one. It is clear that the speaker is now addressing a different point and not the first. Finally, SE.2:13 is used as a marker for demarcation since it is meant by the speaker to alert the hearer that he was concluding on what he had been saying as well as linking the context within the conversation.

The next social event is (SE 3). It is a church meeting and the speakers were a Sunday schoolteacher and the preacher. The Participants were the church members. Let us now look at SE.3:8 and SE.3:12.

SE.3:8 Baubangi (MD)

Next

SE.3:12 Niuntu (MD)

Because

SE 3:8 used in this context to imply that the speaker was moving on to another topic, hence a marker used to show demarcation that allows the audience to pay attention to what the speaker says. As supported by [12], when listeners hear a $\mathrm{DM}$ in speech, they recognize a word in the upcoming speech faster than when they do not hear it. This is because upon hearing the DM, listeners know that they should focus attention on the upcoming utterance. This enhances faster processing of this utterance and thereby proper integration with the prior seg- 
ment. This DM enhances correct interpretation of the utterance as it leaves the listener with none other option than what the optimizes, therefore achieving the goal of the speaker to communicate with his audience. Using SE.3:12 the speaker, who is the preacher here, struggles to remain relevant within the context of a church meeting. She takes charge to make an introduction to the sermon. This DM signals the importance of the upcoming discourse to the audience, hence helps in winning their attention.

Social event four (SE.4) is a burial ceremony. The speakers in this context are Political leaders. Both speakers condoled with the bereaved and addressed the gathering on a number of issues that concerned them. Let us now focus on SE 4:1, SE 4:21, SE 4:30 and SE 4:35.

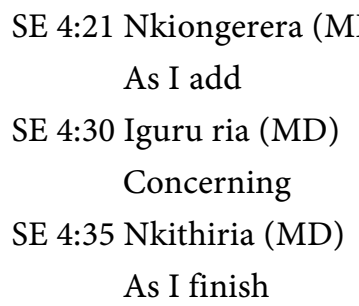

Speaker B justifies his stand using the DM in SE.4:21 by attributing everything to the will of God to imply that there are others who passed on at even tender ages and so the mourners should thank God for the time they had spent with the deceased. SE.4:30 is a DM that brings in a different topic that the opponent to the current speaker (speaker A) had also touched on. The DM in this context serves as a marker of demarcation for it indicates that the speaker has moved on to another topic but within the same context. This is when he used this DM to allude to the point about NHIF rates. SE.4:35 is a discourse marker that the speaker used to remind the audience that although he had come late, he did not intend to take a lot of time and that he was summarizing his turn, though within the same context. The speaker takes a quick note to remind the audience that everyone was a candidate of death and so everyone should know that there is God.

Social event five (SE 5) is a family meeting. It was the last event that was considered for the purposes of this study. Consider SE.5:1 and SE.5:4.

SE 5:4 Kamongereree (MD)

$$
\text { May I add }
$$

The speaker uses SE.5:4 a marker of demarcation in this context to imply that the friendship was meant to last. Table 1 is a summary of the functions of Gichuka discourse markers.

\section{Discussion}

As illustrated in Table 1, most Gichuka discourse markers analyzed in this study served to achieve conversational coherence. Fifty (50) out of the total ninety-two (92) DMs identified were used for that purpose. This represents $54.35 \%$. Markers that served to capture the attention of the audience stand at $23.91 \%$, which is 
Table 1. Summary of the functions of Gichuka discourse markers.

\begin{tabular}{ccc}
\hline Functions of Discourse Markers & Tally & $\%$ \\
\hline Conversational coherence & 50 & 54.35 \\
Attention seeking & 22 & 23.91 \\
Demarcation markers & 09 & 9.78 \\
Turn taking & 05 & 5.43 \\
Request for agreement or confirmation & 03 & 3.26 \\
Filler words & 03 & 3.26 \\
Total & 92 & 100 \\
\hline
\end{tabular}

below half of the CC markers. Demarcation markers stand at $9.78 \%$. The turn taking markers stand at $5.43 \%$. The least tally is that of the filler words and the request for confirmation or agreement that stand at $3.26 \%$.

The reason behind most markers being used to serve the function of conversational coherence in the speeches could be that most speakers struggle to remain relevant, bearing in mind the type of audience that was addressed in each group. The markers that helped to achieve conversational coherence directed the audience towards the speakers meaning. This is important for any form of communication to take place. The attention seeking markers also recorded a high tally, almost half of conversational coherence. This is because all the groups were made up of various classes of people with different levels of understanding. This therefore prompted the speakers to use the attention seeking DMs to capture and retain the attention of the audiences. The demarcation markers recorded the third highest tally because they are mainly used when a speaker begins to address the audience or when ending to show closure. The turn-taking markers took the fourth tally because the speeches were collected from groups that had a number of speakers so each speaker was able to establish his or her turn using a turn-taking DM. Finally, the markers that served to request for agreement or confirmation from the audience recorded the least tally, a similar tally to that of the filler words. This was mainly because most speakers were fluent Gichuka speakers.

As posited by [13], the well-formedness of a text is not achieved by coherence which is signaled by linguistic means alone. Rather, it is achieved pragmatically through the establishment of relevance relations between discourse units. The linking "connecting" words in this case DMs are not linguistic tools that contribute to the interpretation of text through expressing cohesive relations between elements of discourse. Rather, these are pragmatic markers that contribute to the interpretation of a text through controlling relevance relations between discourse units. This study found that DMs have important functions in Gichuka speeches as they helped to establish relevant relations between segments hence guided the audience towards the speakers meaning.

\section{Summary of the Findings}

Fifty (50) discourse markers that served to achieve conversational coherence in 
Gichuka speech were identified from the collected ninety (92) DMs which accounted for (54.35\%) of all the DMs. The study finds this to be the major function that the analyzed Gichuka DMs served in speech. The reason behind this scenario is that, mostly the speakers struggled to remain relevant to be able to pass their messages as much as possible. Specific issues were also addressed in these meetings, so the speaker had all the reasons to guide the hearers towards the right interpretation depending on the speaker's expectations.

Secondly, twenty-two (22) discourse markers that served the function of seeking attention from the audience were identified and this accounted for $23.91 \%$. The DMs that served the function of demarcation markers stood at nine (09) out of ninety-two (92) accounting for $9.78 \%$. The turn taking DMs were five (05) out of ninety-two. This accounted for $5.43 \%$.

The fifth and sixth functions that the identified DMs served are as filler words and request for agreement or confirmation in Gichuka speech. These were equal in tally at $3.26 \%$ each.

\section{Conclusion}

The highest number of Gichuka DMs was used to achieve coherence in speech followed by attention seeking DMs. The demarcation markers, turn taking markers, makers for request for agreement or confirmation and the filler words were occasionally used in the speeches realized.

\section{Conflicts of Interest}

The authors declare no conflicts of interest regarding the publication of this paper.

\section{References}

[1] Fraser, B. (1988) Types of English Discourse Markers. Acta, Linguistica Hungarica.

[2] Fraser, B. (1996) Pragmatic Markers. Pragmatics, 6, 167-190. https://doi.org/10.1075/prag.6.2.03fra

[3] Crystal, D. (1988) The Cambridge Encyclopedia of Language. Cambridge University Press, Cambridge.

[4] Andersen, G. (2001) Pragmatic Markers of Sociolinguistic Variation: A Relevance Theoretic Approach to the Languages of Adolescents. Cambridge University Press, Amsterdam. https://doi.org/10.1075/pbns.84

[5] Akande, A. (2009) Discourse Markers in the Spontaneous Speech of Nigerian University Graduate. Lagos Papers in English Studies, 4, 28-37.

[6] Stenstrom, A. (1990) Lexical Items Peculiar to Spoken Discourse. The London-Lund Corpus of Spoken English. Description and Research. Lund University Press, Lund.

[7] Sperber, D. and Wilson, D. (2002) Relevance: Communication and Cognition. 2nd Edition, Blackwel, Oxford.

[8] Redeker, G. (1991) Ideational and Pragmatic Markers of Discourse Structure. Journal of Pragmatics, 29, 1139-1172. 
[9] Blakemore, D. (2002) Relevance and Linguistic Meaning. The Semantics and Pragmatics of Discourse Markers. Cambridge University Press, Cambridge. https://doi.org/10.1017/CBO9780511486456

[10] Rowling, J. (2002) A Study of the Translation of Discourse Markers in Italian in Harry Potter and the Philosopher's Stone. Linguistics and Languages, Sonia Mariano.

[11] Lenk, U. (1998) Marking Discourse Coherence: Functions of Discourse Markers in Spoken English. Gunter Narr Verlag, Tübingen.

[12] Fatemeh, Z. (2013) Discourse Markers in English. Bieza Islamic Azad University, Bieza.

[13] Miri, H. (2013) English Discourse Markers. Newcastle University, Newcastle. 